\title{
Human-mediated impacts on biodiversity and the consequences for zoonotic disease spillover
}

\author{
Caroline K Glidden ${ }^{1,2}$, Nicole Nova ${ }^{1,2}$, Morgan P Kain ${ }^{1,3}$, Katherine M Lagerstrom ${ }^{1}$, Eloise \\ B Skinner ${ }^{1,4}$, Lisa Mandle ${ }^{1,3,5}$, Susanne H Sokolow ${ }^{5,6}$, Raina K Plowright ${ }^{7}$, Rodolfo Dirzo ${ }^{1,5}$, \\ Giulio A De Leo ${ }^{1,5,8}$, and Erin A Mordecai ${ }^{1,5}$ \\ ${ }^{1}$ Department of Biology, Stanford University \\ ${ }^{2}$ Contributed equally \\ ${ }^{3}$ Natural Capital Project, Stanford University \\ ${ }^{4}$ Centre for Planetary Health and Food Security Griffith University \\ ${ }^{5}$ Woods Institute for the Environment, Stanford University \\ ${ }^{6}$ Marine Science Institute, University of California Santa Barbara \\ ${ }^{7}$ Department of Microbiology and Immunology, Montana State University \\ ${ }^{8}$ Hopkins Marine Station, Stanford University
}

September 15, 2021

\begin{abstract}
Human-mediated changes to natural ecosystems have consequences for both ecosystem and human health. Historically, efforts to preserve or restore 'biodiversity' can seem to be in opposition to human interests. However, the integration of biodiversity conservation and public health has gained significant traction in recent years, and new efforts to identify solutions that benefit both environmental and human health are ongoing. At the forefront of these efforts is an attempt to clarify ways in which biodiversity conservation can help reduce the risk of zoonotic spillover of pathogens from wild animals, sparking epidemics and pandemics in humans and livestock. However, our understanding of the mechanisms by which biodiversity change influences the spillover process is incomplete, limiting the application of integrated strategies aimed at achieving positive outcomes for both conservation and disease management. Here, we review the literature, considering a broad scope of biodiversity dimensions, to identify cases where zoonotic pathogen spillover is mechanistically linked to changes in biodiversity. By reframing the discussion around biodiversity and disease using mechanistic evidence-while encompassing multiple aspects of biodiversity including functional diversity, landscape diversity, phenological diversity, and interaction diversity — we work toward general principles that can guide future research and more effectively integrate the related goals of biodiversity conservation and spillover prevention. We conclude by summarizing how these principles could be used to integrate the goal of spillover prevention into ongoing biodiversity conservation initiatives.
\end{abstract}

\section{Hosted file}

Glidden_Nova_et_al_BiodiversitySpillover_2021_manuscript.pdf available at https://authorea. com/users/330225/articles/525623-human-mediated-impacts-on-biodiversity-and-theconsequences-for-zoonotic-disease-spillover 